\title{
How project-based learning manifests itself in technology education textbooks
}

\author{
Willem Rauscher \\ University of Pretoria, Pretoria, South Africa \\ willem.rauscher@up.ac.za
}

\begin{abstract}
Project-based learning (PBL) is the recommended approach for teaching technology in South Africa. The implementation of this approach, however, is problematic since the vast majority of technology teachers are not formally trained in technology education. Consequently, many of these teachers rely on technology textbooks for guidance. Therefore, the purpose of this study was to investigate how PBL is represented in technology textbooks. A set of criteria, identified by Thomas, capturing the uniqueness of PBL, formed the conceptual framework of this study and was used to conduct the content analysis of twelve of the most commonly used textbooks. The study engaged a combination of quantitative and qualitative research to provide insight into how project-based learning is presented, if at all, in these textbooks. It was found that PBL is poorly represented in the sampled textbooks; the criteria that require projects to be central to the curriculum and to involve learners in a constructive investigation seem to be most problematic. The study recommends that teachers involved in teaching technology deepen their understanding of PBL by studying the theory of this approach, since a proper understanding of PBL in schools is crucial to ensure that we do justice to technology education.
\end{abstract}

Keywords: Project-based learning, technology textbooks, project/capability tasks

\section{Introduction}

The South African Department of Education (DoE) (2003) proposes a project-based approach to teaching technology, i.e. projects should be conducted over an extended period of time using the prescribed design process. Within these longer projects, opportunities for shorter and more focused tasks should be created that aim at building specific skills and knowledge. The DoE (2003) points out that all the required Assessment Standards in technology can be achieved through project-based learning (PBL) experiences.

Despite considerable potential, PBL is not without problems: it is likely to pose difficulties for teachers who may need help with unfamiliar content, new instructional strategies and the implementation and management of projects (Blumenfeld, Soloway, Marx, Krajcik, Guzdial \& Palincsar, 1991). These authors suggest that, without adequate attention to ways of supporting teachers and learners, this innovative educational approach will not be widely adopted.

The DoE (2003) points out that while teachers in South African schools are qualified to teach a variety of subjects, many of the technology teachers are uncomfortable with the pedagogy of technology. This might be ascribed to the fact that the vast majority of practising technology teachers in South Africa do not have formal training in technology education, but were generally sourced from subjects such as home economics, woodwork, metalwork and industrial arts (Van 
Niekerk, Ankiewicz \& De Swart, 2010). Many of the current technology teachers therefore do not have the relevant academic background in terms of the technology content areas, design process and methodological approach to technology education, which includes project-based learning. The lack of guidance with regard to PBL in the National Curriculum Statement (DoE, 2002) exacerbates the situation.

As a result, many technology teachers rely on, inter alia, technology textbooks for guidance. For this reason, the question as to how PBL is represented in technology textbooks needs to be answered. The purpose of this study, therefore, was to determine how PBL manifests in these textbooks. The findings will enhance our understanding of how these teachers are being guided.

\section{Literature review}

PBL draws considerably from the constructivist philosophy of learning, attributed to prominent philosophers of education such as Piaget and Dewey (Barak \& Zadok, 2009). Constructivism is a theory which suggests that the human being is an active learner who constructs his/her knowledge on own experiences and on his/her efforts to give meaning to those experiences (Frank, Lavy \& Elata, 2003). In keeping with the constructivist theory, some of the major characteristics of PBL in technology education include the fact that it is learner centred; that learners can actively discover instead of learning related knowledge; that it allows learners to continuously improve their work or outcomes; that it is challenging and depends upon high-level skills; that it is focused on realistic (reality-related) content and purposes; and that it is focused on realistic (reality-related) evaluation (Lou, Liu, Shih \& Tseng, 2011).

Blumenfeld et al. (1991) describe PBL as a comprehensive approach to classroom teaching and learning that is designed to engage learners in the investigation of authentic problems. Within this approach learners pursue solutions to non-trivial problems by asking and refining questions, debating ideas, making predictions, designing plans, collecting and analysing data, drawing conclusions, communicating their ideas and findings to others, asking new questions, and creating artefacts (Blumenfeld et al., 1991).

The main pedagogical construct for implementing PBL in the classroom is to organize learning around projects. Projects are complex tasks, based on challenging questions or problems, which involve learners in investigative activities, problem-solving, decision making, designing and the making of realistic products (Thomas, 2000). These projects give learners the opportunity to work relatively autonomously over extended periods of time. Projects may last several weeks or as an evolving activity, they may be completed within an academic year or two (Mioduser \& Betzer, 2008).

Thomas (2000) emphasises that projects should embody characteristics of authenticity. Authenticity may apply to the topic, the tasks, the roles that learners play, the context within which the work of the project is carried out, the collaborators who work with learners on the project, the products that are produced, the audience for the project's products, or the criteria by which the products or performances are judged (Thomas, 2000). Middleton (2005) agrees that projects should be authentic, noting that a key feature of any good design and technology classroom is that the activities learners engage in are meaningful. He argues that:

They are meaningful because they have a contingent relationship with the real world that is both inside and outside of the classroom... because they may engage in solving design problems for home, for others, or for the school. Furthermore, the solutions students produce are real solutions from real materials (Middleton, 2005:67). 
Savin-Baden (2003) notes that project-based learning is seen by many as synonymous with problem-based learning because both are regarded as learner-centred approaches to learning. Savin-Baden (2003), however, disagrees and suggests a number of distinct differences between the two approaches, including the fact that in project based learning (PBL) students are required to produce a solution to solve a problem, whereas in problem-based learning the focus is on problem management, not primarily on a clear bound solution.

Notwithstanding the differences, Barron et al. (1998) propose an approach using problembased learning as a scaffold for project-based learning. They argue that project-based learning experiences are frequently organized around a driving question or problem that serves to organize activities which, in turn, result in artefacts or products that address the driving question (Blumenfeld et al., 1991). However, they believe that too frequently the question driving a project is not designed to make connections between activities and the underlying conceptual knowledge one might hope to foster. Barron et al., (1998) proposed that a relevant problembased challenge can serve as a scaffold for more open-ended projects.

Frank et al. (2003) aver that teaching technology by means of PBL may train learners better for their future profession. As in real life, learners in the PBL environment create a synthesis of elements, rather than analysis only. Mioduser and Betzer (2008) concur by claiming that PBL has proven to be a powerful instructional model allowing learners to reach high learning achievements at the expected formal knowledge level.

\section{Conceptual framework}

The conceptual framework of this study is based on a set of criteria, identified by Thomas (2000), which captures the uniqueness of PBL. Although these criteria do not constitute a definition of PBL, they do provide insight into the defining characteristics of a PBL project. Table 1 shows these criteria and provides a brief description of each.

Table 1: Conceptual framework adapted from Thomas's (2000:3-4) criteria for PBL

\begin{tabular}{|l|l|}
\hline Criteria & Brief description \\
\hline $\begin{array}{l}\text { Projects should be central, not } \\
\text { peripheral to the curriculum }\end{array}$ & $\begin{array}{l}\text { According to this criterion, projects are the } \\
\text { curriculum. The project is the central teaching } \\
\text { strategy and learners encounter and learn central } \\
\text { concepts of the subject via the project. Project } \\
\text { work that follows traditional instruction to provide } \\
\text { illustrations, additional practice, or practical } \\
\text { applications for material taught initially by other } \\
\text { means, is not considered to be PBL. }\end{array}$ \\
\hline $\begin{array}{l}\text { Projects involve learners in a } \\
\text { constructive investigation }\end{array}$ & $\begin{array}{l}\text { To be considered a PBL project, the central activities } \\
\text { of the project must involve the construction of "new" } \\
\text { knowledge and skills. If the central activities of the } \\
\text { project present no difficulty to the learner or can be } \\
\text { carried out with the application of already-learned } \\
\text { knowledge or skills, the activity is considered to be } \\
\text { an exercise and not a PBL project. }\end{array}$ \\
\hline
\end{tabular}




\begin{tabular}{|l|l|}
\hline $\begin{array}{l}\text { Projects are focused on questions } \\
\text { or problems that "drive" learners } \\
\text { to encounter the central concepts } \\
\text { and principles of a subject }\end{array}$ & $\begin{array}{l}\text { A “driving question" should be crafted to make a } \\
\text { connection between activities and the underlying } \\
\text { conceptual knowledge. This is usually achieved by } \\
\text { posing an ill-defined problem. }\end{array}$ \\
\hline $\begin{array}{l}\text { Projects are learner-driven to some } \\
\text { significant degree }\end{array}$ & $\begin{array}{l}\text { PBL projects are not teacher-led, scripted, or } \\
\text { packaged. Laboratory exercises and instructional } \\
\text { booklets are not examples of PBL, even if problem- } \\
\text { focused and central to the curriculum. PBL projects } \\
\text { do not have predetermined outcomes or take } \\
\text { predetermined paths. PBL projects provide learners } \\
\text { with much more autonomy, choice, unsupervised work } \\
\text { time, and responsibility than traditional instruction } \\
\text { and traditional projects. }\end{array}$ \\
\hline $\begin{array}{l}\text { Projects are realistic, not school- } \\
\text { like }\end{array}$ & $\begin{array}{l}\text { PBL incorporates real-life challenges where the } \\
\text { focus is on authentic (not simulated) problems or } \\
\text { questions and where solutions have the potential to } \\
\text { be implemented. }\end{array}$ \\
\hline
\end{tabular}

\section{Technology in the South African curriculum}

The purpose of technology education in South Africa is, according to the DoE (2002), to contribute towards learners" technological literacy, which the DoE defines as "the ability to use, manage, and assess technology" (DoE, 2002:66). This purpose is to be achieved through an integration of the three learning outcomes stated in the Revised National Curriculum Statement (RNCS) for grades R-9 (schools) for technology as summarised in Table 2.

Table 2: Summary of the three learning outcomes in technology education (DoE, 2002:6-9)

\begin{tabular}{|l|l|}
\hline Learning Outcome & Summary \\
\hline Learning outcome 1 & $\begin{array}{l}\text { This is the backbone outcome for the Technology Learning Area. } \\
\text { In this outcome the learner will be able to apply technological } \\
\text { processes and skills ethically and responsibly using appropriate } \\
\text { information and communication technologies. }\end{array}$ \\
\hline Learning outcome 2 & $\begin{array}{l}\text { In this outcome the learner will be able to understand and apply } \\
\text { relevant technological knowledge ethically and responsibly. } \\
\text { Three core content areas are prescribed, namely structures, } \\
\text { processing, and systems and control. }\end{array}$ \\
\hline Learning outcome 3 & $\begin{array}{l}\text { This outcome states that the learner will be able to } \\
\text { demonstrate an understanding of the interrelationships } \\
\text { between science, technology, society and the environment. The } \\
\text { achievement of this learning outcome will ensure that learners } \\
\text { are aware of indigenous technology and culture, impacts of } \\
\text { technology, and biases created by technology. }\end{array}$ \\
\hline
\end{tabular}

The technology learning outcomes are totally integrated and should be delivered that way. Learning outcome 1 is the main learning outcome of technology and should be used to structure 
the delivery of all the learning outcomes. Learning outcome 2 provides learners with the range of knowledge contexts that must be used to develop relevant learning programmes. Learning outcome 3 will usually be integrated within the contexts of Learning outcome 2 (DoE, 2003).

In technology, projects are intended to use the design process, i.e. an integration of skills of investigating, designing, making, evaluating and communicating, as prescribed by the DoE (2003). These projects are often referred to as capability tasks as they should develop learners' capability in the three learning outcomes. Capability tasks, according to Barlex (2000), involve designing and making a product that works.

Whilst conducting capability tasks, learners must be provided with opportunities to build knowledge and skills through structured and focused tasks such as resource tasks and case studies. Resource tasks are short practical activities used to help learners acquire the knowledge and skills they need to competently design and make (Barlex, 2000). Case studies, on the other hand, are true stories about design and technology in the world outside the classroom.

\section{Research design}

\section{Mode of inquiry}

A combination of a quantitative and qualitative research approach was used to investigate a sample of technology textbooks. The quantitative phase engaged a deductive content analysis to provide insight into the extent to which PBL is represented in these textbooks. A deductive analysis approach draws on an existing theory or model (White \& Marsh, 2006). This method seems appropriate since Thomas's (2000) criteria, which formed the conceptual framework of this study, were used to guide the analysis.

Qualitative discussions of a number of cases, i.e. projects or capability tasks presented in the textbooks, were included to complement the quantitative data. These case discussions are also based on the criteria listed in the conceptual framework and aim to inform how PBL is portrayed in the textbook as well as to relate each case to the school curriculum.

\section{Sampling}

The sampling frame consists of textbooks that are listed in the DoE textbook catalogue which offers a vast variety of technology textbook titles schools may choose from. Texts range in comprehensiveness, in their expectations of the curriculum as well as the level of difficulty pertaining to the content. With the help of a publication company the most commonly used technology textbooks for the senior phase (grades 7-9) were purposively selected. The senior phase was targeted since technology is presented in this phase as a separate learning programme unlike in the earlier phases of the General Education and Training (GET) band. Attempts were made to include at least two, preferably three (one per grade in the senior phase) textbooks from each of the limited number of frequently used publishers. Eleven textbooks, believed to be representative of what the vast majority of schools use in the GET band, were used for this study.

The sampled textbooks were scrutinised to find activities labelled by the authors as projects or capability tasks. They were selected to represent what was typical in each book. Even when the "projects" were no more than "making" activities or resource tasks, it was decided to include these "projects" in the analysis since they were presented as projects/capability tasks in the 
textbooks and the intension of this study is to determine how PBL manifests itself in textbooks in order to understand how technology teachers are being guided by textbooks.

Twenty-four projects/capability tasks were selected for the quantitative analysis. The criterion used for determining the sample size was based on the principle of redundancy of information, which suggests that sampling should be terminated when no new information is forthcoming from new units, i.e. data saturation (Ary, Jacobs \& Razavieh, 2002; Lincoln \& Guba, 1985). It was decided to stop after analysisng twenty-four projects/capability tasks as the same formats of PBL were repeated by the same authors. These trends were also consistent across the different books by the various publishers.

Projects/capability tasks were selected for discussion in the qualitative phase on the basis of a range of results in terms of fulfilling the PBL criteria in the quantitative phase of this study. Four examples, ranging from a low to a high match with the PBL criteria, were included for discussion.

\section{Analysis methodology}

Each project/capability task was evaluated against each PBL criterion to determine whether the task complies with the requirements of a PBL project. In the quantitative analysis, a 1 was allocated if the task met the criterion and a 0 was assigned if not. These results were tabled and frequencies were counted to indicate how often each PBL criterion was represented in the sample.

During the qualitative analysis the selected project/capability tasks were critiqued using the PBL criteria in the conceptual framework as reference. Apart from validating the quantitative findings, the purpose of the qualitative discussions is to show how PBL is portrayed in technology textbooks. This analysis relates the tasks to the school curriculum and orientates the reader with regard to the intended outcomes in technology.

The dependability of the study was enhanced by means of an inter-rater reliability measure which was achieved by asking a second technology educator to independently analyse twelve (50\%) randomly selected project/capability tasks. An inter-rater agreement of $90 \%$ was calculated using the formula posed by Jackson (2006) which exceeds to recommended minimum agreement of at least $80 \%$ for good reliability (Miles \& Huberman, 1994).

Truthfulness was established by means of content validity, i.e. how much a measure covers the range of meanings included within the concept (Babbie \& Mouton, 2011). This was achieved by using the criteria in the conceptual framework, which constitute the requirements of a project for PBL, to guide the analysis.

In addition, each project/capability task was analysed within the broader context of the complete textbook, e.g. the way the task is presented and the placement within each chapter. Some tasks are presented at the beginning of the chapter with the intention to make the task central to the curriculum, whilst other tasks are presented at the end of the chapter and should be conducted with the application of already-learned knowledge or skills.

\section{Results and discussion}

The sample of project/capability tasks was analysed using the criteria which are listed as the requirements for a PBL project in the conceptual framework. It was found that none of the 
projects/tasks (referred to as 'examples' from here on) selected for this study complied with all of the criteria of a PBL project as summarised in Table 3.

Table 3: Characteristics of project-based learning (PBL) projects

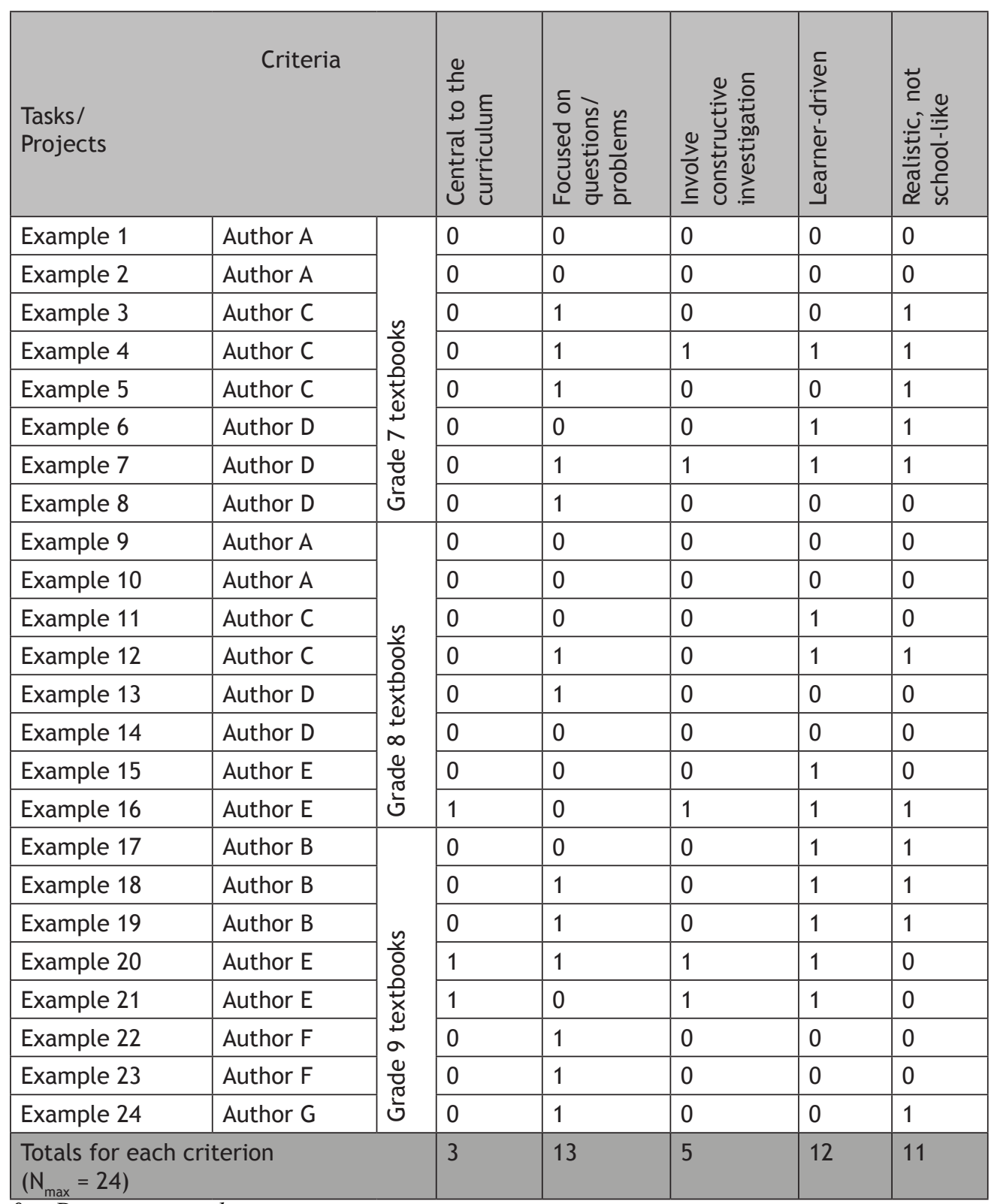

$0=$ Does not meet the criterion.

$1=$ Meets the terms of the criterion. 
Table 3 shows that project-based learning (PBL) is only very partly represented in the sampled technology textbooks. The criteria that seem to be most problematic are those that require projects to be central to the curriculum and to involve learners in a constructive investigation. A possible reason for the aforementioned results is that most of the sampled tasks focus on the conceptual knowledge in Learning outcome 2, instead of using the project and Learning outcome 1 as the "backbone outcome", to structure and integrate the other two learning outcomes.

A detailed discussion of a selection of the examples will now be presented. It should, again, be emphasised that these examples were evaluated within the broader context of the textbook, and should therefore not be judged in isolation.

\section{Example 1}

Example 1 appears in a Grade 7 textbook:

Design and make a steam engine which can turn a crank axle that will move the vehicle forward. You will need: a cold drink can, plastic tubes, sealant, cylinder, connection rod, slider, plastic wheels, crank axle, cotton, water, nails, glue, wood, paraffin, matches, saw, curved saw and tin foil (Author A, 2005:49).

This task is presented in the textbook as a capability task to address mechanisms which are part of the systems and control content area in Learning outcome 2. The related assessment standard states:

[the learner] demonstrates knowledge and understanding of mechanical systems that change a direction of movement using components (e.g. cams, pistons, pivot and slider, eccentric wheels), and/or the value of force in systems (e.g. lever systems, linked lever systems, pneumatic or hydraulic systems), and represents them using systems diagrams (DoE, 2002:48).

Example 1 met none of the criteria listed in the conceptual framework. Each criterion will now be discussed separately with regard to Example 1.

Thomas (2000:3) points out that "projects are the curriculum". Projects should be used as the central teaching strategy through which learners can learn all the concepts that pertain to the subject. Task 1, however, focuses on Learning outcome 2 only, and does not integrate the other learning outcomes as is expected by the RNCS. Despite the inclusion of the word "design" in the task, no designing activities are required to make this model as a list of all the materials and components as well as detailed instructions and sketches are included to show exactly how to construct it. Also, the learner does not have to make value judgements on any issues, such as the impact of technology, or bias in technology, as prescribed in Learning outcome 3 . The knowledge and skills relevant to Learning outcome 1, the main learning outcome, and Learning outcome 3 will therefore not be addressed in this task. In addition, the task seems to be a practical application of material that was already taught. The task in Example 1 can therefore not be considered to be central to the curriculum.

An essential component of a PBL project is a question that "drives" learners to encounter the core concepts and principles of a subject (Thomas, 2000). Task 1, however, is not driven by an ill-defined problem or question; it is simply an activity that requires the learner to construct a model using a detailed sketch and a predetermined list of components. Learners can, therefore, built the model without any conceptual problem solving involved. 
Another requirement of a PBL project involves the transformation and construction of "new" knowledge and skills. The activities involved in completing a PBL project must present some difficulty to the learner and engage the learner in a constructive investigation. This criterion is not met by Example 1 since the task can be carried out with the application of already-learned knowledge and by merely following the instructions provided by the textbook - no constructive investigation by learners is required.

Thomas (2000) asserts that PBL projects are learner-driven and consequently do not end up at a predetermined outcome or take predetermined paths. In Example 1, the textbook author scripted the activity in such a way that the learners do not have any choice as to how the model could work or what it might look like. The learners are required to use the prescribed list of materials and the sketch provided in the wording of the task. Task 1 is therefore not learner-driven: it has a predetermined path and all learners will produce replicas of the same model.

PBL projects must be realistic, not school-like, and the solutions must have the potential to be implemented (Thomas, 2000). Example 1 does not meet this criterion either since it does not solve any authentic need. It is a school-like activity that has no potential for implementation as it has no utility value outside the classroom, apart from developing skills.

Although Example 1 is presented in the textbook as a capability task, it does not comply with what is generally considered to be a capability task. The learners will, for example, not engage in any designing activities or constructive investigation. It seems that Example 1 is in fact a resource task and not a capability task: it is a short practical activity that can be used to teach learners the knowledge, understanding and skills likely to be required in capability tasks (Barlex, 1998).

\section{Example 11}

Example 11 appears in a Grade 8 textbook:

A local primary school asks you to design and make outdoor benches for them. They want benches for the Senior/Intermediate Phase as well as the Foundation Phase. Present them with scale models of two benches that are made of different materials and are manufactured using different processing methods. You must apply what you have learned about processing from this chapter in each of the benches (Author C, 2008:55).

This task is presented in the textbook to address the processing content area in Learning outcome 2. The related assessment standard states:

Demonstrates knowledge and understanding of how materials can be processed to change or improve their properties by adapting them to suit particular purposes: to withstand forces (e.g. tension, compression, bending, torsion, and shear); to increase strength or life-span; how specific properties suitable for packaging can be achieved (DoE, 2002:47).

Example 11 met one of the five criteria listed in the conceptual framework, namely that it is learner-driven. Each criterion will now be discussed separately with regard to Example 11.

The task presented in Example 11 ends with an instruction by the author that the learners must apply what they have learned about processing from that chapter in the textbook, when they conduct this task. Example 11 consequently is not central to the curriculum as all the knowledge required by the assessment standard for processing in Learning outcome 2 , is acquired before the 
learners engage the task. As a result, the activity is simply a practical application for knowledge that is acquired initially by other means.

Example 11 includes an instruction that the learner should present a local primary school with scale models of two benches that are made of different materials and are manufactured using different processing methods. Although it is clear that the school wants outdoor benches for the Senior/Intermediate Phase as well as the Foundation Phase, there is no driving question embedded in the task that can frame the activity or that needs solving. It therefore does not comply with the requirement that a PBL project should be focused on a driving question or problem.

Since the author expects the learners to carry out the task with the application of already-learned knowledge and skills, the task cannot be considered to be a PBL project. The criterion that insists that a PBL project involves learners in constructive investigation is not met.

Following the task shown in Example 11, the textbook lists the different phases of the design process, signalling that the learner must use the design process to design and make the models. The integration of Learning outcome 1 with Learning outcome 2 provides the learners with much more autonomy as the designing phase of the design process, for example, calls for different solutions to be generated and design choices to be made. Learners are hence free to create their own designs. There is therefore no predetermined outcome as the models can take any shape or size and should be made from different materials and manufactured using different processing methods. The task in Example 11 thus meets the criterion that requires PBL projects to be learner-driven to some significant degree.

Although the local primary school wants outdoor benches, the task entails the designing and making of models of benches. These models can, alas, not be tested against the real-life conditions, for example to withstand forces such as tension, compression and bending resulting from children sitting on the bench. The task is therefore a simulation where the solution cannot be implemented and as a result does not meet the requirement that a PBL project must incorporate a real-life challenge.

\section{Example 16}

Example 16 appears in a Grade 8 textbook:

At the end of this module you need to have made a personal decoration or piece of jewellery for a friend in the class. This friend will act as your client and will determine the specifications and limitations of the design brief, which you need to work on together. You must take into account your friend's beliefs, likes and dislikes and the function for which he or she wants the decoration. You also need to be the client of another friend in the class, as he or she needs to design and make jewellery for you (Author E, 2006:94).

This task is presented in the textbook to address the processing content area in Learning outcome 2. The assessment standard is shown in Example 11 above.

Example 16 met four of the five criteria listed in the conceptual framework. Only the criterion that states that a PBL project must be focused on a question or problem is not met. Each criterion will now be discussed separately with regard to Example 16. 
The task presented in Example 16 is one of the few examples found in the sampled textbooks that meet the criterion which requires a PBL project to be central to the curriculum. The task is presented at the beginning of the chapter on processing. The rest of the chapter offers a range of activities, such as investigation, resource and designing tasks, through which the learner will engage and learn the knowledge required to make the piece of jewellery. Working through all the activities not only realises the assessment standard of Learning outcome 2, but also integrates Learning outcome 1 and Learning outcome 3: learners are guided through the design process whilst having to consider indigenous methods of processing metals.

The task is presented as an instruction to make a personal decoration or piece of jewellery for a friend in the class. Although problems might arise while making the jewellery, the task itself does not present a driving problem that needs solving. The task therefore does not meet the criterion which needs a PBL project to be focused on a driving question/problem.

The range of activities presented after the task engages learners in various investigation and evaluation activities as well as experiments. These include, for example, the investigation of different forces and how the materials used in jewellery can be strengthened to withstand these forces. During these activities, the learners are required to construct new knowledge and skills which should enable them to make the personal decoration. The criterion which requires that a PBL project must involve constructive investigation is thus met by this task.

The task states that learners must take into account their friend's beliefs, likes and dislikes and the function for which (s)he wants the decoration/jewellery. There is therefore no predetermined outcome as learners will have a significant degree of autonomy and choice when they make this piece of decoration. The task thus complies with the requirement that a PBL project should be learner-driven.

The task also meets the criterion stating that PBL projects must be realistic, not school-like. The task is based on a real-life want and has the potential to be implemented as the learners will be able to use their piece of jewellery.

\section{Example 19}

Example 19 features in a Grade 9 textbook

Your family uses a storage tank for water. You need a detector to warn you when the tank is full so that you can pump some water out into the garden. Design and build a detector that could be used to detect the water level in the tank (Author B, 2006:158).

This task is presented in the textbook to address the systems and control content area in Learning outcome 2. The assessment standard in the RNCS states:

Demonstrates knowledge and understanding of how simple electronic circuits and devices are used to make an output respond to an input signal (e.g. resistors, light-emitting diodes, transistors, push or magnetic switches, thermistors, light-dependent resistors) (DoE, 2002:49).

Task 19 met three of the five criteria listed in the conceptual framework, namely that it is focused on a question/problem, learner-driven and realistic. Each criterion will now be discussed separately with regard to Example 19. 
The task, related to electrical systems and control, presented in Example 19 is one of three "projects" presented at the end of the chapter on systems in this textbook. The other two "projects" relate to the mechanical systems and control assessment standard in Learning outcome 2. Learners have to choose one of these "projects" and then follow the design process to design and make the artefact. This option indicates that learners first have to work through all the knowledge (both mechanical and electrical) on systems and control in the chapter, before engaging the activity. The task thus does not comply with the requirement that a PBL project must be central to the curriculum as the material is taught initially by other means and not learnt through the "project".

The problem alluded to in this task is that the water storage tank will overflow without a level detector that can warn if the level in the tank rises too high. In solving this problem, the learners must engage the underlying conceptual knowledge with regard to electrical system and control to be able to design and make a detector. The task hence meets the criteria which states that a PBL project must focus on a driving question or problem.

The task is conducted only after the knowledge relating to this task was taught by other means. Also, a circuit diagram, which can be used as a solution to this problem, is presented and discussed in the text of the earlier chapter on electrical systems. The task consequently presents no difficulty to the learner and no new knowledge needs to be constructed by the learner. This task therefore does not meet the criterion specifying that PBL projects must involve learners in constructive investigation.

Although the textbook provides a circuit diagram according to which the learner can construct the solution, the task allows for many choices making the outcome to this task unpredictable. The task, for example, does not prescribe what the warning system should entail. Learners are also free to choose what the final artefact will look like, for example its shape, colour and size. The task therefore complies with the requirement that a PBL project must be learner-driven to some significant degree.

A well-made level detection and warning system has utility value outside of the classroom that is not necessarily limited to water level detection in a water tank. Other possible applications can include the detection of the water level in a swimming pool or bath. It therefore meets the PBL project criterion that states that it must be realistic and have the potential to be implemented.

\section{Conclusion}

The results from this study show that project-based learning (PBL) is only partially represented in the most commonly used technology textbooks. It was found that none of the typical tasks that were analysed complied with all of the criteria of a PBL project. The criteria that were least often represented in the sample are the criteria that require projects to be central to the curriculum, and that projects must involve learners in a constructive investigation. The evidence shows that the lack of these criteria may be the result of the textbooks' emphasis on the knowledge in Learning outcome 2 at the cost of, inter alia, Learning outcome 1, which is actually the main learning outcome of technology. The design process is often omitted or dealt with very superficially as an additional activity. While learners should engage with the underlying conceptual knowledge in the designing and making of a solution, most tasks follow traditional instruction only for the purpose of providing practical applications for material taught initially by other means. This limits the possibility for the learner to construct and transform "new" knowledge and skills. 
It was also found that several of the sampled tasks are not inspired by ill-defined problems, and often lacked authenticity. These tasks are frequently found to be "making" instructions where the solution has no utility value outside the classroom. This causes one to question the meaningfulness of these activities in terms of knowledge production. Middleton (2005) asserts that activities are meaningful only if learners engage in solving real design problems to produce real solutions from real materials. In addition, Barron et al. (1998) propose an approach using a driving problem or question which can serve as a scaffold for project-based learning. This driving question allows connections between the activities and the underlying conceptual knowledge that one might hope to foster.

Some tasks, although presented in the textbook as "capability tasks" are no more than resource tasks, i.e. short practical activities. This might be an indication of the author's poor understanding of the characteristics of PBL, or it might be due to the expectations and needs of the publication company which may require a prescribed text format. Further investigation is required to establish the reasons for these misrepresentations.

The findings of this study provide evidence for inadequate manifestation of PBL in the sampled textbooks. This suggests that many teachers are not guided according to the requirements of the prescribed methodological approach to teaching technology, which includes PBL. It is, therefore, recommended that teachers involved in teaching technology, deepen their understanding of PBL by studying the theory of this approach. Institutions such as Universities involved in the training of technology teachers should factor these findings into their training: making the studentteachers, for example, aware of the textbooks' shortcomings and providing them with a sound methodological approach to teaching technology, which includes PBL. A proper understanding and implementation of PBL in schools is crucial to ensure that we do justice to technology education.

\section{References}

Ary, D., Jacobs, L. C., \& Razavieh, A. (2002). Introduction to research in education. Belmont: Wadsworth/ Thomson learning.

Babbie, E., \& Mouton, J. (2011). The practice of social research. Cape Town: Oxford University Press.

Barak, M., \& Zadok, Y. (2009). Robotics projects and learning concepts in science, technology and problem solving. International Journal of Technology and Design Education, 19(3), 289-307.

Barlex, D. (1998). Design and technology - the Nuffield perspective in England and Wales. International Journal of Technology and Design Education, 8(2), 139-150.

Barlex, D. (2000). Perspectives on departmental organisation and children's learning through the Nuffield design and technology project. In J. Eggleston (ed.), Teaching and learning design and technology (pp. 91-103). London: Continuum.

Barron, B. J. S., Schwartz, D. L., Vye, N. J., Moore, A., Petrosino, A., \& Zech, L.(1998). Doing with understanding: Lessons from research on problem- and project-based learning. The Journal of the Learning Sciences, 7(3 \& 4), 271-311.

Blumenfeld, P. C., Soloway, E., Marx, R. W., Krajcik, J. S., Guzdial, M., \& Palincsar, A. (1991). Motivating project-based learning: Sustaining the doing, Supporting the learning. Educational Psychologist, $26(3$ \& 4), 369-398. 
Department of Education. (2002). National Curriculum Statement for Grades R-9 (Schools) for Technology. Pretoria: Department of Education.

Department of Education. (2003). Revised National Curriculum Statement Grades R-9 (Schools): Teacher's guide for the development of learning programmes - Technology.

Frank, M., Lavy, I., \& Elata, D. (2003). Implementing the project-based learning approach in an academic engineering course. International Journal of Technology and Design Education, 13(3), 273-288.

Jackson, S. L. (2006). Research methods and statistics: A critical thinking approach. Singapore: Thomson Wadsworth.

Lincoln, Y. S., \& Guba, E. G. (1985). Naturalistic inquiry. Beverly Hills, CA: Sage.

Lou, S. J., Liu, Y. H., Shih, R. C., \& Tseng, K. H. (2011). The senior high school students' learning behavioral model of STEM in PBL. International Journal of Technology and Design Education, 21(2), 161-183.

Middleton, H. (2005). Creative thinking, values and design and technology education. International Journal of Technology and Design Education, 15(1), 61-71.

Miles, M. B., \& Huberman, A. M. (1994). Qualitative data analys: A sourcebook of new methods. CA: Sage.

Mioduser, D., \& Betzer, N. (2008). The contribution of Project-based-learning to high-achievers' acquisition of technological knowledge and skills. International Journal of Technology and Design Education, 18(1), 59-77.

Savin-Baden, M. (2003). Facilitating problem-based learning. Berkshire: Society for Research into Higher Education \& Open University Press.

Thomas, J. W. (2000). A review of research on project-based learning. Autodesk Foundation. Retrieved July 26, 2011, from http://www.bie.org/research/study/review of project based learning 2000

Van Niekerk, E., Ankiewicz, P., \& De Swart, E. (2010). A process-based assessment framework for technology education: A case study. International Journal of Technology and Design Education, 20(2), $191-215$

White, M. D., \& Marsh, E. (2006). Content analysis: A flexible methodology. Library Trends, 55(1), $22-45$. 